\title{
Criteria for using proficiency test results for estimation of measurement uncertainty: feed analysis example
}

\author{
Waldemar Korol $^{1}$ • Jolanta Rubaj ${ }^{1}$ - Grażyna Bielecka ${ }^{1}$ - Sławomir Walczyński ${ }^{1}$. \\ Joanna Reszko-Zygmunt ${ }^{2} \cdot$ Ryszard Dobrowolski $^{2}$
}

Received: 12 October 2016/Accepted: 13 February 2017/Published online: 3 March 2017

(C) The Author(s) 2017. This article is published with open access at Springerlink.com

\begin{abstract}
On the basis of long-standing proficiency testings (PTs) for the small number of PT participants $p(7 \leq p \leq 30)$, laboratory bias and uncertainty were calculated by applying inter-laboratory experimental approaches. Uncertainty was estimated in two ways, according to Eurolab TR No 1/2007 and Nordtest TR 537 (2012). In the case of 24 tested feed components (basic nutrients, macro- and microelements, undesirable elements and some feed additives including vitamins $\mathrm{A}$ and $\mathrm{E}$, lysine, threonine, methionine and urea) in the large variety of feed samples, differences between the expanded uncertainties calculated according to Eurolab TR No 1/2007 and Nordtest TR 537 did not exceed $1.4 \%$ for all tested feed and analytes in wide concentration ranges. In order to get a reliable evaluation of bias and uncertainty, minimum of 6 PT rounds and a sufficient number of laboratories participating $(p \geq 10)$ are recommended. When the above parameters are applied and the standard deviation of the bias $s_{\text {bias }} \leq 5 \%$, the expression $s_{\text {bias }}^{2} / n$ can be omitted while calculating bias. Generally, both approaches fit the purpose of feed evaluation and the calculated uncertainties can be used for compliance assessment.
\end{abstract}

Keywords Feed proficiency testing - Bias - Uncertainty · Practical approach $\cdot$ Within-laboratory reproducibility

Ryszard Dobrowolski

rdobrow@poczta.umcs.lublin.pl

1 National Research Institute of Animal Production, National Laboratory for Feedingstuffs, St. Chmielna 2, 20-079 Lublin, Poland

2 Department of Analytical Chemistry and Instrumental Analysis, Faculty of Chemistry, Maria Curie-Sklodowska University, M. C. Sklodowska Sq. 3, 20-031 Lublin, Poland

\section{Introduction}

Animal feed stuff includes different and variable matrices, and the test results of feed components and their measurement uncertainties should fit the intended purpose especially when used for compliance assessment [1]. Some laboratories underestimate the levels of uncertainties of their results and report unrealistically small values of some parameters to their customers. Therefore, the predicted levels of measurement uncertainties for food and feed were established for official testing in the EU, derived from the Horwitz equation [2,3]. One of the possible approaches to estimate measurement uncertainty in a laboratory involves combining all uncertainty components responsible for random and systematic errors affecting measurement result according to GUM [4]. The examples of calculating measurement uncertainties are given in the Eurachem/CITAC Guide [5]. One of the essential sources of uncertainty is heterogeneity of the sample materials.

However, during the routine analysis of feed materials characterized by different matrices it is usually assumed that homogeneity and stability of studied materials are acceptable. This assumption is too optimistic in the case of feed additives and also due to lack of knowledge on the long term stability of analytes. On the other hand, in order to obtain reliable values the following conditions should be fulfilled. First, the samples tested in PTs should be similar to the routine feed ones, in the scope of both feed matrices variety and tested substance contents. It is important that PTs are organized in conformity with well-recognized standards, e.g., with ISO 17043 [6]. That is why it is important to verify measurement uncertainty using experimental approaches.

The basis for the experimental approaches to assess measurement uncertainty with the use of the test results of 
certified reference materials (CRM) or the results of laboratory participation in proficiency tests (PTs) are presented in the Eurolab Technical Report (TR) No 1/2007 [7] and in the Nordtest Handbook [8]. These approaches, known as practical ones, were also mentioned in the latest Eurachem/ CITAC Guide CG 4 [5] and in the ISO 11352:2012 standard [9]. According to the Eurachem/CITAC Guide [5], the data obtained from PTs can provide useful information for assessing measurement uncertainty in the laboratory. Moreover, PT providers can obtain better similarity of tested materials than routine samples typically analyzed in a laboratory.

Due to difficulties in accessing feed CRMs, a laboratory may use the results from participation in PTs for estimating measurement uncertainty. While evaluating the uncertainty of analyte measurement on the basis of the data from PTs, a laboratory should assess their own results as well as to verify the quality and accuracy of PTs.

The aim of this paper was to compare the measurement uncertainties of several feed components (basic nutrients, minerals, feed additives, undesired substances) calculated on the basis of experimental approaches using the PT results with those obtained according to GUM [4] and predicted uncertainties calculated from the Horwitz equation $[2,10]$. In detail, the difference between the two approaches, according to Eurolab TR [7] and Nordtest TR [8], for calculation of measurement uncertainty from PTs was evaluated, especially in a small number of PT participants $p(7 \leq p \leq 30)$ and the obtained uncertainty values were estimated in accordance to requirements for compliance assessment.

\section{Materials and methods}

\section{Materials and the scope of PTs}

Test materials were the feed samples analyzed in PTs, organized in the years 2004-2013 by the National Laboratory for Feeding stuffs (NLF) in the scope of a reference activity. The aim of PTs was to assess the competence of official feed supervision laboratories and to use the results of PTs for validation and accreditation of test methods. Until 2009, PTs had been prepared in conformity with the ISO/IEC 43-1 guide [11] and since 2010 in conformity with the ISO 17043 standard [6]. More than 50 samples of different feeds were analyzed, including 10 samples of feed materials, nearly 30 samples of complete feed mixtures, 5 samples of supplementary feed mixtures and 8 samples of premixtures. Moreover, NLF has participated in 10 international PT rounds organized by the reference laboratories from the EU countries in which 84 samples of feed materials, feed mixture and premixtures were tested. The scope of PTs included testing of basic nutrients (moisture, crude protein, crude fat, crude ash, crude fiber, starch and sugars), macroelements $\left(\mathrm{Ca}, \mathrm{Na}, \mathrm{K}, \mathrm{Cl}^{-}\right)$, microelements $(\mathrm{Fe}, \mathrm{Mn}$, $\mathrm{Zn}, \mathrm{Cu}, \mathrm{Co}, \mathrm{Se}$ ), feed additives such as amino acids (lysine, methionine, threonine) and vitamins (A and $\mathrm{E}$ ), as well as urea and undesirable elements $(\mathrm{Pb}, \mathrm{Cd}, \mathrm{As})$. A total number of 429 results of these tests were used in the paper for evaluation of measurement uncertainty.

The reference materials were used for measurement uncertainty calculation based on the within-laboratory experimental approach, namely certified reference material NCS ZC73013 Spinage (Beijing, China) for $\mathrm{Co}, \mathrm{Cd}, \mathrm{Pb}$ and As and reference material CS-M-2 Dried Mushroom (produced and certified by Institute of Nuclear Chemistry and Technology, Warsaw, Poland) for Se.

\section{Procedures}

Basic nutrients (moisture, crude ash, crude protein, crude fat, crude fiber, starch and sugar), urea, vitamins A and E, lysine, methionine and threonine were tested by means of official procedures given in regulation 152/2009 [12]. Macro- and microelements such as calcium, magnesium, sodium, potassium, manganese, zinc and copper were analyzed by flame atomic absorption spectrometry after adequate sample treatment according to ISO 6869 [13]. Selenium and arsenic were tested by atomic absorption spectrometry with hydride generation HGAAS according to standard methods $[14,15]$. Lead, cadmium and cobalt were determined by graphite furnace atomic absorption spectrometry (GF AAS) [16].

\section{Calculating uncertainty on the basis of PT results}

It is worth noting that data from proficiency testing (PT) can provide useful information for uncertainty evaluation. It means that for methods in laboratory use for a long time, data from proficiency testing practical approach can be used for checking the estimated uncertainty with results from PT exercises for a laboratory. On the other hand, a laboratory can applied this attitude for estimation of measurement uncertainty.

Combined standard uncertainty $u_{\text {rel }}$ was calculated as a root sum of squares of a within-laboratory reproducibility $R S D_{\mathrm{w}}$ characterizing the precision of the measurement and bias $b$, according to Eq. (1). The expanded uncertainty $U_{\text {rel }}$ was calculated with the use of coverage factor $k=2$, $U_{\text {rel }}=u_{\text {rel }} \cdot 2$.

$u_{\mathrm{rel}}=\sqrt{R S D_{\mathrm{w}}^{2}+b^{2}}$

Bias was calculated following Eq. (2) presented in the Eurolab Technical Report No 1/2007 [7] 
$b=\sqrt{\Delta_{\mathrm{RMSbias}}^{2}+u_{\mathrm{PT}}^{2}+\frac{s_{\text {bias }}^{2}}{n}}$

where $\Delta_{\mathrm{RMSbias}}$ is the root mean square of the bias values, $u_{\mathrm{PT}}=1.25 s_{\mathrm{PT}} / \sqrt{ } n$ is standard uncertainty of the assigned value calculated according to ISO 13528 [17]; $s_{\text {bias }}$ is standard deviation of the bias determination; $n$ is number of PT rounds, or using Eq. (3) presented in the Nordtest Handbook [8].

$b=\sqrt{\Delta_{\mathrm{RMSbias}}^{2}+u_{\mathrm{PT}}^{2}}$

The root mean square of the bias $\Delta_{\text {RMSbias }}$ was calculated following Eq. (4)

$\Delta_{\mathrm{RMSbias}}=\sqrt{\frac{\sum\left(X_{1 \ldots n}-X_{\mathrm{PT} 1 \ldots \mathrm{n}}\right)^{2}}{n}}$

where $X_{1 \ldots n}$ is NLF results in PT rounds; $X_{\mathrm{PT} 1 \ldots n}$ is assigned values of PT rounds. For the reason of extended measuring ranges, relative uncertainties, biases and precision parameters (in \%) are used in the paper.

Data of the within-laboratory reproducibilities $R S D_{\mathrm{w}}$, bias data $s_{\text {bias }}$ and results in PT rounds $X_{1 \ldots n}$ were obtained by NLF. The within-laboratory reproducibilities $R S D_{\mathrm{w}}$ originated from control charts. Assigned values as consensus values $X_{\mathrm{PT} 1 \ldots n}$ were obtained from PTs.

To assess the quality of PT precision, the Horwitz' ratio (HorRat, $H$ ) was calculated as the quotient of $s_{\mathrm{PT}} / \sigma$ where $\sigma$ is the target standard deviation obtained from the Horwitz equation $\sigma=2 \cdot C^{-0.15}$ in which $C$ is the dimensionless mass fraction (accepted values: $0.5<H<2$ ) and $s_{\mathrm{PT}}$ is the standard deviation from a PT [10].

On the basis of Horwitz equation, the target relative standard deviation of reproducibility $R S D_{\mathrm{R}}$ was obtained and used for calculation uncertainty, including bias data from PTs. For comparison with within-laboratory reproducibilities $R S D_{\mathrm{w}}, R S D_{\mathrm{R}}$ was recalculated to obtain target, $R S D_{\mathrm{WR}}=0.67 \cdot R S D_{\mathrm{R}}$, according to Horwitz and Albert [10]. Combined standard uncertainty $u_{\text {rel }}$ was calculated as a root sum of squares of a target within-laboratory reproducibility $R S D_{\mathrm{w}}$ and bias $b$ obtained by laboratory using the Eurolab TR approach [7], according to Eq. (1). The expanded uncertainty $U_{\text {rel }}$ was calculated with the use of coverage factor $k=2$ and put in the last column of Table 1.

In the case of basic nutrients, expanded uncertainties were calculated according to permitted tolerances given in the Commission Regulation (EU) No 939/2010 [18]. It was assumed that contribution homogeneity and uncertainty in permitted tolerances are the same and permitted uncertainty $U_{\text {prel }}(\%)$ can be obtained by multiplying relative permitted tolerances by factor 0.7 . Permitted uncertainties for basic nutrients $U_{\text {prel }}(\%)$ are presented in the last column of Table 1.

\section{Results and discussion}

The results of bias and measurement uncertainty for the basic nutrients in feed are presented in Table 2. Whichever Eqs. (2) or (3) was used to determine bias, the differences between the bias results to some degree depended on the size of $s_{\text {bias }}$ and generally were not larger than $0.25 \%$. Expanded uncertainties for basic nutrients calculated on the basis of Eurolab TR [7] or Nordtest TR [8] were considerably lower than the permitted analytical tolerances (expanded uncertainties) calculated on the basis of the Regulation 939/2010 [18], indicating that both approaches fit the purpose in the frame of feed evaluation (Table 1). High HorRat value for sugar equal to 2.41 indicated low precision of PTs for this nutrient, and according to Horwitz and Albert [10] this is the example of the method-defined analyte. Precision of such methods such as titrimetric method for determination of mass fraction of sugar or gravimetric methods for determination of mass fraction of crude fiber is usually high within a single laboratory (see Table 2, sugar: low value of withinlaboratory reproducibility $R S D_{\mathrm{w}}=1.12 \%$ ) and low among different laboratories (high value of relative standard deviation of sugar mass fraction from PTs, high HorRat value equal to 2.41). However, expanded uncertainty of the titrimetric method for determination mass fraction of sugar, obtained by two approaches, was acceptable and according to requirements [18].

In case of minerals and toxic elements, the differences between biases calculated according to Eurolab TR [7] and Nordtest TR [8] and those between the combined standard uncertainties with bias share did not exceed $0.3 \%$ (Tables 3 , 4). Both approaches fit the purpose taking into account predicted expanded uncertainties based on the Horwitz' equation and laboratory biases (Table 1).

The results of the two methods of calculating bias and combined standard uncertainty for feed additives, amino acids and urea were similar and the differences did not exceed $0.3 \%$ (Table 5). In the case of vitamins $\mathrm{A}$ and $\mathrm{E}$ in feed mixtures and premixtures where $s_{\text {bias }}$ ranged between $5.6 \%$ and $8.6 \%$, the differences between the bias and uncertainty values calculated from Eqs. (2) and (3) were larger but did not exceed $1.3 \%$. At smaller PT precision, especially for vitamins $\mathrm{A}$ and $\mathrm{E}$ in premixtures $(H$ from 2.09 to 2.27 ), the obtained biases and combined standard uncertainties were larger than for the other additives. The reason for such results may be inhomogeneity of test samples, isolated from the laboratory bulk samples before determinations. Some PT providers sent feed samples to PT 
Table 1 Evaluation of the results of expanded uncertainties on the basis of the data from PTs, calculated according to GUM [4] and predicted using the Horwitz equation

\begin{tabular}{|c|c|c|c|c|c|}
\hline $\begin{array}{l}\text { Analyzed component } \\
\text { Basic nutrients }\end{array}$ & $\begin{array}{l}\text { Range } \\
\mathrm{g} / \mathrm{kg}\end{array}$ & $\begin{array}{l}\text { Mean value } \\
\mathrm{g} / \mathrm{kg}\end{array}$ & $\begin{array}{l}U_{\text {rel }}(k=2) \\
\text { (from PTs), [7]/[8] } \\
\%\end{array}$ & $\begin{array}{l}U_{\text {rel }}(k=2) \\
(\mathrm{GUM}) \\
\%\end{array}$ & $\begin{array}{l}\text { Predicted } U_{\text {rel }}(k=2) \\
\text { Horwitz/ } U_{\text {prel }} \\
\%\end{array}$ \\
\hline Crude ash & $51-354$ & 85 & $6.7 / 6.7$ & 4.0 & $6.2 / 8.7^{\mathrm{e}}$ \\
\hline Crude protein & $147-352$ & 205 & $4.8 / 4.7$ & 4.0 & $5.6 / 8.7^{\mathrm{e}}$ \\
\hline Crude fiber & $26-58$ & 36 & $11.7 / 11.3$ & 7.0 & $10.7 / 33^{\mathrm{e}}$ \\
\hline Crude fat & $20-39$ & 31 & 11.2/11.0 & 4.0 & $11.9 / 23^{\mathrm{e}}$ \\
\hline Starch & $246-455$ & 405 & $7.4 / 7.3$ & 3.0 & $7.4 / 6.0^{\mathrm{e}}$ \\
\hline Sugars & $17-86$ & 49 & $13.0 / 12.7$ & 6.0 & $13.4 / 24^{\mathrm{e}}$ \\
\hline Macroelements & $\mathrm{g} / \mathrm{kg}$ & $\mathrm{g} / \mathrm{kg}$ & $\%$ & $\%$ & $\%$ \\
\hline $\mathrm{Ca}$ & $7.35-34.5$ & 15.3 & $8.7 / 8.5$ & 9.6 & 8.8 \\
\hline $\mathrm{Mg}$ & $1.70-4.32$ & 2.36 & $10.0 / 9.7$ & 8.0 & 11.1 \\
\hline $\mathrm{Na}$ & $1.43-3.63$ & 2.78 & $12.0 / 11.6$ & 11.6 & 12.6 \\
\hline $\mathrm{K}$ & $6.04-16.6$ & 9.84 & $10.3 / 10.2$ & 9.0 & 11.1 \\
\hline $\begin{array}{l}\text { Microelements and } \\
\text { toxic elements }\end{array}$ & $\mathrm{mg} / \mathrm{kg}$ & $\mathrm{mg} / \mathrm{kg}$ & $\%$ & $\%$ & $\%$ \\
\hline Mn & $56.1-415$ & 212 & $9.1 / 8.7$ & 12.0 & 12.1 \\
\hline $\mathrm{Zn}$ & $40.6-342$ & 177 & $12.3 / 12.1$ & 10.4 & 13.2 \\
\hline $\mathrm{Cu}$ & $14.4-37.1$ & 23.6 & 15.1/14.6 & 15.0 & 18.9 \\
\hline $\mathrm{Co}$ & $0.40-2.84$ & 0.85 & $24.6 / 24.2$ & $24.0^{\mathrm{a}}$ & 29.5 \\
\hline $\mathrm{Se}$ & $0.31-0.93$ & 0.53 & $22.8 / 22.2$ & $15.0^{\mathrm{a}}$ & 31.4 \\
\hline As & $0.09-17.2$ & 4.29 & $17.7 / 17.3$ & $25.0^{\mathrm{a}}$ & 21.4 \\
\hline $\mathrm{Cd}$ & $0.03-1.66$ & 0.69 & $22.4 / 22.2$ & $24.0^{\mathrm{a}}$ & 27.6 \\
\hline $\mathrm{Pb}$ & $0.46-10.1$ & 3.64 & $20.6 / 20.0$ & $16.0^{\mathrm{a}}$ & 22.5 \\
\hline Feed additives & $\mathrm{g} / \mathrm{kg}$ & $\mathrm{g} / \mathrm{kg}$ & $\%$ & $\%$ & $\%$ \\
\hline Vitamin $A^{b}$ (pr.) & $0.566-1.38^{\mathrm{b}}$ & $0.852^{\mathrm{b}}$ & $17.6 / 17.2$ & 18.1 & 18.0 \\
\hline Vitamin $A^{b}$ (f.m.) & $0.0024-0.0122^{\mathrm{b}}$ & $0.00623^{\mathrm{b}}$ & $22.8 / 20.2$ & 20.3 & 25.2 \\
\hline Vitamin $E^{c}$ (pr.) & $0.9-15.2^{\mathrm{c}}$ & $7.98^{\mathrm{c}}$ & $13.4 / 12.8$ & 14.0 & 14.5 \\
\hline Vitamin $E^{c}$ (f.m.) & $0.073-0.114^{\mathrm{c}}$ & $0.100^{\mathrm{c}}$ & $18.3 / 16.5$ & 16.0 & 20.8 \\
\hline Lysine & $6.5-78.2$ & 20.6 & $9.3 / 9.3$ & $10.0^{\mathrm{d}}$ & 8.8 \\
\hline Methionine & $4.5-13.7$ & 7.2 & $15.3 / 15.0$ & $15.0^{\mathrm{d}}$ & 14.7 \\
\hline Threonine & $5.6-28.6$ & 13.2 & $9.6 / 9.5$ & $17.0^{\mathrm{d}}$ & 9.7 \\
\hline Urea & $12.5-106$ & 51.4 & $12.2 / 11.8$ & 10.0 & 11.9 \\
\hline
\end{tabular}

pr. premixture, f.m. feed mixture

[7]/[8] — comparison of expanded uncertainties calculated according to Eurolab TR [7] and Nordtest TR [8]

${ }^{\text {a }}$ Uncertainty calculated using CRMs results

b Calculated as retinol

${ }^{c}$ Calculated as tocopherol acetate

d Calculated from PTs in the years 2004-2008

e $U_{\text {prel }}$ calculated on the basis of permitted tolerances given in the regulation (EU) No 939/2010 [18]

participants in the same way as the samples obtained from customers, i.e., without grinding. The problem of inhomogeneity is important, especially in the case of vitamins $A$ and $E$ and other unstable substances which are specifically protected in feed against oxidation and other destructive factors [19]. In the case of lysine, threonine, methionine and urea, satisfactory PT precision was noted ( $H$ from 0.92 to 1.32 ). For methionine (Table 5 ), relatively high uncertainty resulted mainly from a wide range of within-laboratory reproducibility $(5.37 \%)$.

Results in Table 1 present expanded uncertainties calculated based on the data from PTs according to Eurolab 
Table 2 Evaluation of bias $b$ and uncertainty $u$ for basic nutrients in feed materials and feed mixtures on the basis of PT data and withinlaboratory reproducibility

\begin{tabular}{|c|c|c|c|c|c|c|c|c|c|c|c|}
\hline \multirow[t]{2}{*}{ Nutrient } & \multirow[t]{2}{*}{$n$} & \multirow[t]{2}{*}{$p$} & \multirow{2}{*}{$\begin{array}{l}\text { Range } \\
(\mathrm{g} / \mathrm{kg})\end{array}$} & \multirow{2}{*}{$\begin{array}{l}\text { Mean value } \\
(\mathrm{g} / \mathrm{kg})\end{array}$} & \multirow[t]{2}{*}{ Mean $H$} & \multirow{2}{*}{$\begin{array}{l}R S D_{\mathrm{w}} \\
(\%)\end{array}$} & \multirow{2}{*}{$\begin{array}{l}s_{\text {bias }} \\
(\%)\end{array}$} & \multicolumn{2}{|c|}{ Eurolab TR [7] } & \multicolumn{2}{|c|}{ Nordtest TR [8] } \\
\hline & & & & & & & & $\overline{b(\%)}$ & $u(\%)$ & $b(\%)$ & $u(\%)$ \\
\hline Crude ash & 25 & 25 & 51-354 & 85 & 0.90 & 2.37 & 2.03 & 2.39 & 3.37 & 2.36 & 3.35 \\
\hline Crude protein & 21 & 27 & $147-352$ & 205 & 0.55 & 0.76 & 2.13 & 2.26 & 2.39 & 2.21 & 2.34 \\
\hline Crude fiber & 9 & 21 & $26-58$ & 36 & 1.39 & 3.20 & 4.44 & 4.89 & 5.84 & 4.65 & 5.65 \\
\hline Crude fat & 12 & 26 & $20-39$ & 31 & 1.69 & 0.76 & 3.29 & 5.54 & 5.60 & 5.45 & 5.50 \\
\hline Starch & 15 & 16 & $246-455$ & 405 & 1.24 & 1.59 & 3.23 & 3.36 & 3.72 & 3.26 & 3.63 \\
\hline Sugar & 11 & 9 & $17-86$ & 49 & 2.41 & 1.12 & 4.22 & 6.39 & 6.48 & 6.25 & 6.35 \\
\hline
\end{tabular}

$n$ number of PT rounds, $p$ mean number of laboratories in PTs, $H$ Horwitz' ratio (HorRat)

Table 3 Evaluation of bias $b$ and uncertainty $u$ for macroelements in feed materials and feed mixtures on the basis of PT data and withinlaboratory reproducibility

\begin{tabular}{|c|c|c|c|c|c|c|c|c|c|c|c|}
\hline \multirow[t]{2}{*}{ Element } & \multirow[t]{2}{*}{$n$} & \multirow[t]{2}{*}{$p$} & \multirow{2}{*}{$\begin{array}{l}\text { Range } \\
(\mathrm{g} / \mathrm{kg})\end{array}$} & \multirow{2}{*}{$\begin{array}{l}\text { Mean value } \\
(\mathrm{g} / \mathrm{kg})\end{array}$} & \multirow[t]{2}{*}{ Mean $H$} & \multirow{2}{*}{$\begin{array}{l}R S D_{\mathrm{w}} \\
(\%)\end{array}$} & \multirow{2}{*}{$\begin{array}{l}S_{\text {bias }} \\
(\%)\end{array}$} & \multicolumn{2}{|c|}{ Eurolab TR [7] } & \multicolumn{2}{|c|}{ Nordtest TR [8] } \\
\hline & & & & & & & & $b(\%)$ & $u(\%)$ & $b(\%)$ & $u(\%)$ \\
\hline $\mathrm{Ca}$ & 11 & 18 & $7.35-36.1$ & 15.3 & 1.39 & 2.41 & 3.04 & 3.62 & 4.35 & 3.49 & 4.24 \\
\hline $\mathrm{Mg}$ & 11 & 18 & $1.70-4.32$ & 2.36 & 1.24 & 2.27 & 4.05 & 4.44 & 4.99 & 4.27 & 4.84 \\
\hline $\mathrm{Na}$ & 10 & 17 & $1.43-7.07$ & 2.78 & 1.27 & 2.69 & 4.90 & 5.38 & 6.01 & 5.13 & 5.79 \\
\hline $\mathrm{K}$ & 10 & 17 & $6.04-16.6$ & 9.84 & 1.42 & 1.92 & 3.65 & 4.77 & 5.14 & 4.73 & 5.11 \\
\hline
\end{tabular}

$n$ number of PT rounds, $p$ mean number of laboratories in PTs, $H$ Horwitz' ratio (HorRat)

Table 4 Evaluation of bias $b$ and uncertainty $u$ for microelements and undesirable elements in feed materials, feed mixtures and premixtures (only for undesirable elements) on the basis of PT data and within-laboratory reproducibility

\begin{tabular}{|c|c|c|c|c|c|c|c|c|c|c|c|}
\hline \multirow[t]{2}{*}{ Element } & \multirow[t]{2}{*}{$n$} & \multirow[t]{2}{*}{$p$} & \multirow{2}{*}{$\begin{array}{l}\text { Range } \\
(\mathrm{mg} / \mathrm{kg})\end{array}$} & \multirow{2}{*}{$\begin{array}{l}\text { Mean value } \\
(\mathrm{mg} / \mathrm{kg})\end{array}$} & \multirow[t]{2}{*}{ Mean $H$} & \multirow{2}{*}{$\begin{array}{l}R S D_{\mathrm{w}} \\
(\%)\end{array}$} & \multirow{2}{*}{$\begin{array}{l}S_{\text {bias }} \\
(\%)\end{array}$} & \multicolumn{2}{|c|}{ Eurolab TR [7] } & \multicolumn{2}{|c|}{ Nordtest TR [8] } \\
\hline & & & & & & & & $b(\%)$ & $u(\%)$ & $b(\%)$ & $u(\%)$ \\
\hline Mn & 8 & 20 & $56.1-415$ & 212 & 1.28 & 2.60 & 3.07 & 3.74 & 4.55 & 3.52 & 4.37 \\
\hline $\mathrm{Zn}$ & 13 & 30 & $40.6-342$ & 177 & 0.71 & 4.29 & 4.17 & 4.43 & 6.17 & 4.27 & 6.06 \\
\hline $\mathrm{Cu}$ & 8 & 16 & $14.4-37.1$ & 23.6 & 0.82 & 3.50 & 5.64 & 6.72 & 7.58 & 6.42 & 7.31 \\
\hline Co & 8 & 18 & $0.40-2.84$ & 0.85 & 1.05 & 7.20 & 5.20 & 9.93 & 12.2 & 9.76 & 12.1 \\
\hline $\mathrm{Se}$ & 6 & 13 & $0.31-0.93$ & 0.53 & 1.36 & 4.43 & 6.37 & 10.5 & 11.4 & 10.2 & 11.1 \\
\hline As & 7 & 11 & $0.09-17.2$ & 4.29 & 0.59 & 6.06 & 5.35 & 6.47 & 8.87 & 6.15 & 8.63 \\
\hline $\mathrm{Cd}$ & 13 & 19 & $0.03-1.66$ & 0.69 & 0.64 & 7.84 & 6.80 & 8.03 & 11.2 & 7.81 & 11.1 \\
\hline $\mathrm{Pb}$ & 8 & 17 & $0.46-10.1$ & 3.64 & 0.88 & 4.71 & 6.77 & 9.14 & 10.3 & 8.86 & 10.0 \\
\hline
\end{tabular}

$n$ number of PT rounds, $p$ mean number of laboratories in PTs, $H$ Horwitz' ratio (HorRat)

TR [7] and Nordtest TR [8] in comparison with those obtained according to GUM [4] and predicted using the Horwitz equation and bias from PTs. Differences between expanded uncertainties calculated according to Eurolab TR No 1/2007 and Nordtest TR 537 did not exceed $2.6 \%$ for all tested feed and analytes in large concentration ranges and did not exceed predicted uncertainties obtained from the Horwitz equation.

For the basic nutrients, such as crude fiber, crude fat, starch and sugars, uncertainties calculated according to GUM [4] were lower, even by a half, than those calculated on the basis of PT results. In the case of minerals analyzed 
Table 5 Evaluation of bias $b$ and uncertainty $u$ for some feed additives in feed materials, feed mixtures and premixtures on the basis of PT data and within-laboratory reproducibility

\begin{tabular}{|c|c|c|c|c|c|c|c|c|c|c|c|}
\hline \multirow[t]{2}{*}{ Feed additive } & \multirow[t]{2}{*}{$n$} & \multirow[t]{2}{*}{$p$} & \multirow{2}{*}{$\begin{array}{l}\text { Range } \\
(\mathrm{g} / \mathrm{kg})\end{array}$} & \multirow{2}{*}{$\begin{array}{l}\text { Mean value } \\
(\mathrm{g} / \mathrm{kg})\end{array}$} & \multirow[t]{2}{*}{ Mean $H$} & \multirow{2}{*}{$\begin{array}{l}R S D_{\mathrm{w}} \\
(\%)\end{array}$} & \multirow{2}{*}{$\begin{array}{l}S_{\text {bias }} \\
(\%)\end{array}$} & \multicolumn{2}{|c|}{ Eurolab TR [7] } & \multicolumn{2}{|c|}{ Nordtest TR [8] } \\
\hline & & & & & & & & $b(\%)$ & $u(\%)$ & $b(\%)$ & $u(\%)$ \\
\hline Vit. $A^{\mathrm{a}}$ (pr.) & 9 & 8 & $0.566-1.38^{\mathrm{a}}$ & $0.852^{\mathrm{a}}$ & 2.09 & 3.40 & 5.58 & 8.11 & 8.79 & 7.90 & 8.60 \\
\hline Vit. $A^{\mathrm{a}}$ (f.m.) & 8 & 13 & $0.0024-0.0122^{\mathrm{a}}$ & $0.00623^{\mathrm{a}}$ & 0.93 & 4.00 & 7.65 & 10.6 & 11.4 & 9.32 & 10.1 \\
\hline Vit. $E^{b}$ (pr.) & 8 & 9 & $0.90-15.2^{\mathrm{b}}$ & $7.98^{\mathrm{b}}$ & 2.27 & 2.00 & 5.58 & 6.40 & 6.71 & 6.09 & 6.41 \\
\hline Vit. $E^{\mathrm{b}}$ (f.m.) & 5 & 24 & $0.073-0.114^{\mathrm{b}}$ & $0.100^{\mathrm{b}}$ & 1.22 & 1.00 & 8.65 & 9.08 & 9.13 & 8.21 & 8.27 \\
\hline Lysine & 17 & 10 & $6.5-78.2$ & 20.6 & 0.95 & 3.06 & 2.50 & 3.53 & 4.67 & 3.49 & 4.64 \\
\hline Methionine & 5 & 12 & $4.5-13.7$ & 7.2 & 1.32 & 5.37 & 4.37 & 5.42 & 7.63 & 5.22 & 7.49 \\
\hline Threonine & 11 & 8 & $5.6-28.6$ & 13.2 & 0.92 & 2.71 & 3.49 & 3.98 & 4.81 & 3.89 & 4.74 \\
\hline Urea & 6 & 7 & $12.5-106$ & 51.4 & 1.28 & 2.48 & 3.89 & 5.57 & 6.10 & 5.33 & 5.89 \\
\hline
\end{tabular}

$n$ number of PT rounds, $p$ mean number of laboratories in PTs, $H$ Horwitz' ratio, $p r$. premixture, f.m. feed mixture

${ }^{a}$ Calculated as retinol

${ }^{\mathrm{b}}$ Calculated as tocopherol acetate

by the FAAS method ( $\mathrm{Ca}, \mathrm{Mg}, \mathrm{Na}, \mathrm{K}, \mathrm{Mn}, \mathrm{Zn}$ and $\mathrm{Cu}$ ), uniformity was noted for the uncertainties calculated following GUM and on the basis of PT results. It is possible to assume measurement uncertainty calculated on the basis of PT results for these elements and to use them to control the quality of the tests, e.g., following the NATA recommendations [20]. In the case of $\mathrm{Co}, \mathrm{Se}, \mathrm{As}, \mathrm{Cd}$ and $\mathrm{Pb}$ measurement uncertainties were calculated on the basis of the within-laboratory experimental approach using of CRM (Table 1). They were similar to those obtained from PTs and generally smaller than those calculated according to the Horwitz equation. Measurement uncertainties for vitamins $\mathrm{A}$ and $\mathrm{E}$ in the premixtures and feed mixtures calculated on the basis of PT results were lower than those obtained using the Horwitz equation and generally fit the purpose.

\section{Conclusions}

In conclusion, the data from PTs in the scope of feed analysis can be used for estimation of laboratory bias and, on the basis of bias and within-laboratory reproducibility, measurement uncertainty can be determined. The precision of PTs can be verified against the Horwitz ratio (HorRat, $H$ ) and the satisfactory level of this parameter is in the range $0.5<H<2$ were obtained. It is obvious that only laboratory results with $z$-score or zeta-score $\leq 2$, should be used in bias calculation.

In order to obtain reliable evaluation of bias and uncertainty, a minimum of 6 PT rounds is recommended. Moreover, PTs should be characterized by accepted precision and a sufficient number of laboratories $(p \geq 10)$. When the above requirements are met and the standard deviation of the bias $s_{\text {bias }} \leq 5 \%$, the expression $s_{\text {bias }}^{2} / n$ can be omitted while calculating bias.

The protocol of bias and uncertainty calculation on the basis of PTs presented in the paper refers mainly to the given laboratory. The uncertainty calculated as presented in the paper can be used as a check for the uncertainty calculated according to GUM [4]. Uncertainty is useful in expressing the results for feed components or undesirable substances providing help in interpreting the results. While testing animal feed, the measurement uncertainty is used to (1) assess the maximum content of feed additives in feed mixtures, (2) estimate the share of undesirable substances in relation to the requirements defined by regulations and (3) verify the information provided on the label concerning feed additives and their permitted tolerances according to the Commission Regulation (EU) No 939/2010 [18]. The PT results of designated laboratories that can carry out the analysis of feed samples taken during official controls, using the same official feed analysis methods, can be used to create a uniform, inter-laboratory system for assessing uncertainty and interpreting tests results, useful for conformity assessment.

Acknowledgements The authors are grateful to Professor Dr. Joseph H. Rule from Old Dominion University (Norfolk, VA), USA, and his wife Dr. Anna M. Rule for their help with the English preparation of the manuscript.

Open Access This article is distributed under the terms of the Creative Commons Attribution 4.0 International License (http:// creativecommons.org/licenses/by/4.0/), which permits unrestricted use, distribution, and reproduction in any medium, provided you give appropriate credit to the original author(s) and the source, provide a link to the Creative Commons license, and indicate if changes were made. 


\section{References}

1. Bettencourt da Silva R, Williams A (eds) (2015) Setting and using target uncertainty in chemical measurement. In: Eurachem/ CITAC Guide www.eurachem.org

2. Horwitz W (2003) The certainty of uncertainty. J AOAC Int 86:109-111

3. Report on the relationship between analytical results, measurement uncertainty, recovery factors and the provisions of EU Food and Feed legislation. http://ec.europa.eu/food/food/chemicalsafety/ contaminants/report sampling_analysis_2004_en.pdf

4. Guide to the expression of uncertainty in measurement (GUM) (1993) ISO Geneva; also JCMG 100. http://www.bipm.org/en/ publications/guides/gum

5. Ellison SLR, Williams A (eds) (2012) Eurachem/CITAC guide: quantifying uncertainty in analytical measurements. www. eurachem.org

6. EN ISO/IEC 17043:2010 Conformity assessment-General requirements for proficiency testing. CEN, Brussels

7. EUROLAB Technical Report 1/2007 (2007) Measurement uncertainty revisited: Alternative approaches to uncertainty evaluation Eurolab Paris. http://www.eurolab.org

8. Magnusson B et al (2012) Handbook for calculation of measurement uncertainty in environmental laboratories. NORDTEST Report TR 537 Edition 3.1. http://www.nordtest.info

9. ISO 11352:2012 Water quality-estimation of measurement uncertainty based on validation and quality control data. ISO, Geneva

10. Horwitz W, Albert R (2006) The Horwitz ratio (HorRat): a useful index of method performance with respect to precision. J AOAC Int 89:1095-1109

11. ISO/IEC Guide 43-1:1997 Proficiency testing by interlaboratory comparisons: part 1: development and operation of proficiency testing schemes. ISO, Geneva
12. Commission Regulation (EC) No $152 / 2009$ of 27 January 2009 laying down the methods of sampling and analysis for the official control of feed. Official Journal of the European Union, 2009, L54, 1-130

13. EN ISO 6869:2000 Animal feeding stuffs-determination of the contents of calcium, copper, iron, magnesium, manganese, potassium, sodium and zinc-method using atomic absorption spectrometry. CEN, Brussels

14. EN 16159:2012 Animal feeding stuffs-determination of selenium by hydride generation atomic absorption spectrometry (HGAAS) after microwave digestion. CEN, Brussels

15. EN 16206:2012 Animal feeding stuffs-determination of arsenic by hydride generation atomic absorption spectrometry (HGAAS) after microwave pressure digestion. CEN, Brussels

16. EN 15550:2007 Animal feeding stuffs-determination of cadmium and lead by graphite furnace atomic absorption spectrometry (GF-AAS) after pressure digestion. CEN, Brussels

17. ISO 13528:2015 Statistical methods for use in proficiency testing by interlaboratory comparisons. ISO, Geneva

18. Commission Regulation (EC) No 939/2010 of 20 October 2010 amending Annex IV to regulation (EC) No 767/2009 on permitted tolerances for the compositional labelling of feed materials or compound feed as referred to in Article 11(5). Official Journal of the European Union, 2010, L277, 4-7

19. Korol W et al (2015) Uncertainty from sample preparation in the laboratory on the example of various feeds. Accred Qual Assur 20:61-66. doi:10.1007/s00769-014-1096-x

20. NATA Technical Note 33 (2013) Guidelines for estimating and reporting measurement uncertainty of chemical results. http:// www.health.gov.au/internet/main/publishing.nsf/Content/717802 D80CFD8A4ACA257BF0001BDBB7/\$File/technical_note_33. pdf 